\title{
Estimating the Impact of Medicare Part D on the Profitability of Independent Community Pharmacies
}

\author{
Norman V. Carroll, PhD
}

\begin{abstract}
BACKGROUND: Medicare Part D provides insurance coverage for prescription drugs to elderly and disabled consumers. Part D accounted for $24 \%$ of prescriptions dispensed by independent pharmacies in the first year of the program (2006). To date, the impact of Part $D$ on independent pharmacies has been explored only in small, qualitative, or non-peer-reviewed studies.

OBJECTIVE: To develop preliminary estimates of the impact of Part $D$ on independent pharmacies' profitability.

METHODS: A financial model was built to examine the impact of Part $D$ on pharmacy profitability. A key input value was the gross margin percentage for Part D; the midpoint of estimates reported in the literature was used as the base-case input value. The remaining model inputs were derived from 2 non-peer-reviewed published sources: (a) the National Community Pharmacist Association (NCPA)'s survey of independent pharmacies, which provided financial data for the year prior to Part D implementation (2005); and (b) IMS Health national market research data, which provided information about changes in prescription drug utilization from 2005 to 2006. Model estimates represented a "typical" independent pharmacy, defined using mean values for financial measures in 2005 as reported by NCPA. The model examined the impact of Part $D$ on the proportion of prescriptions reimbursed by other sources (private third-party insurance, Medicaid, and cash payments by patients); pharmacies' overall prescription gross margin; the number of Part D-induced prescriptions; the number of prescriptions lost to mail-order pharmacies; and net income before taxes. Key values and assumptions were subjected to one-way and probabilistic sensitivity analyses.

RESULTS: The model indicated that implementation of Part $D$ resulted in a mean (SD) $22 \%(4 \%)$ decrease in net income before taxes. This change was primarily the result of an absolute $0.7 \%$ decline in the gross margin for all prescriptions. The lower overall gross margin resulted from lower reimbursement on Part D prescriptions. In the typical independent community pharmacy, Part D induced an increase in utilization of an estimated 427 prescriptions but 229 prescriptions were lost to mail-order pharmacies. The results were most sensitive to Part $D$ reimbursement rates. Even under the most optimistic assumptions, Part D decreased net income. However, even under the least favorable assumptions, the typical independent pharmacy remained profitable.
\end{abstract}

CONCLUSION: Part D reduced the profitability of the typical independent pharmacy by an estimated mean (SD) $22 \%(4 \%)$ in 2006. This reduction resulted primarily from the lower Part $\mathrm{D}$ reimbursement rates.

J Manag Care Pharm. 2008;14(8):768-79

Copyright $\odot$ 2008, Academy of Managed Care Pharmacy. All rights reserved.

\section{What is already known about this subject}

- Part D provided reimbursement for $24 \%$ of prescriptions dispensed in independent pharmacies and $14.6 \%$ of all community and mail-order pharmacies in 2006. Part D's effect is growing; the percentage of prescriptions covered by Part D was substantially higher in the second 6 months of 2006 than in the first 6 months.

- Part D increased prescription drug utilization only moderately in 2006, by $3.9 \%$ among Part D enrollees in an analysis of a national pharmacy chain. Utilization increases may have been moderate because only 14\% of Part D enrollees paid for their drugs entirely out-of-pocket in the year before enrolling in Part D.

- A few studies have examined the impact of Part D on pharmacy gross margins. The 2007 NCPA-Pfizer Digest (for 2006 data) estimated gross margins of $19.6 \%$ for Medicaid, $18.5 \%$ for private third parties, and $16 \%$ for Part D. Winegar et al. estimated margins of $27.0 \%$ for Medicaid versus 20.4\% for Part D.

\section{What this study adds}

- Part D was associated with an absolute $0.7 \%$ decline in the typical independent pharmacy's gross margin percent for prescriptions.

- In 2006, Part D induced an estimated increase in utilization of 427 prescriptions among Part D enrollees at the typical independent pharmacy. However, 229 prescriptions were lost to mail order.

- Part D has decreased the net income of the typical independent pharmacy by a mean (SD) 22\% (4\%), primarily due to lower reimbursement rates.

$\mathrm{T}$ he Medicare Part D prescription drug program was implemented on January 1, 2006. Part D was intended to fill a major gap in the Medicare program by providing insurance coverage for prescription drugs to elderly and disabled consumers, many of whom would otherwise lack coverage. The literature, while providing widely varying estimates, indicates that Part D has been successful in providing prescription drug insurance to many elderly consumers who would otherwise not be insured. For example, Neuman et al., based on a national 
survey of 16,000 elderly Medicare beneficiaries, estimate that one-third of elderly consumers lacked drug coverage in 2005 and that $61 \%$ of these enrolled in Part D plans in 2006. ${ }^{1}$ When these results are extrapolated to the U.S. elderly population (37 million in 2005²), about 7.5 million elderly consumers gained drug coverage as a result of Part D. IMS Health (IMS), based on information from its proprietary database of over 5,400 commercial and Medicare plans, estimates that 3.4 million consumers gained access to drug coverage as a result of Part D during 2006. ${ }^{3}$ The Kaiser Family Foundation reports that 23.9 million consumers were enrolled in Part D plans as of January $2007^{4}$

Early estimates indicate that Part D has increased prescription drug utilization only moderately. Yin et al. report that among patients of a large, national, chain pharmacy, Part D-related average monthly utilization increased $1.1 \%$ in the first 5 months of the program and $5.9 \%$ in the next 10 months. ${ }^{5}$ IMS reports that total utilization (utilization due to Part D and all other effects) among Part D beneficiaries increased by 3\% for patients formerly on Medicaid, $10 \%$ for those formerly enrolled in private thirdparty plans, and by $26 \%$ for those with no prior insurance for prescription drugs. ${ }^{3}$

Part of the reason for the small increase in utilization may be that most Part D recipients had insurance for prescription drugs prior to enrolling in Part D. While the 26\% increase in prescription drug utilization for the group with no prior drug insurance was substantial, IMS indicates that only 14\% of Part D enrollees paid for their drugs entirely out of pocket in the year before enrolling in Part D. A total of 58\% previously had private third-party coverage for prescriptions and $24 \%$ were covered by Medicaid. The remaining 4\% had drug coverage from multiple sources during the year. ${ }^{3}$

Because of its effects on prescription sales and reimbursement, Part D could have a major impact on the profitability of community pharmacies in at least 3 ways. First, the limited evidence available to date suggests that Part D is likely to result in lower gross profit margins on prescriptions dispensed in community pharmacies. ${ }^{6-9}$ (The gross profit on a prescription is the difference between the amount the pharmacy is reimbursed for a prescription and the amount the pharmacy paid for the drug product dispensed. The gross profit margin is the gross profit divided by the amount the pharmacy was reimbursed and multiplied by 100.) Because most Part D beneficiaries had prescription drug coverage prior to their Part D enrollment, many prescriptions that previously were reimbursed out-of-pocket (cash), by private thirdparty plans, or by Medicaid are now covered by Part D plans. Gross margins on prescriptions reimbursed by Medicaid, cash, or by private third parties typically yield higher margins than those reimbursed by Part D. ${ }^{6,7}$ For example, the 2007 National Community Pharmacist Association (NCPA) NCPA-Pfizer Digest estimates gross margins of $19.6 \%$ for Medicaid prescriptions, $18.5 \%$ for private third-party prescriptions, and $16 \%$ for prescriptions reimbursed by Part D.7 Thus, the change to Part D payment for prescriptions that were previously, or would otherwise have been, reimbursed by cash, Medicaid, or private third-party insurance results in a lower gross margin for the pharmacy.

Second, providing prescription drug insurance to patients who would otherwise be uninsured should increase the total volume of prescriptions dispensed. All else equal, this change should increase community pharmacies' prescription sales. Third, Part D may induce a shift of prescription volume from community pharmacies to mail-order pharmacies. This shift would occur because Part D plans, like most private third-party programs, usually offer consumers substantial financial incentives to have maintenance prescriptions dispensed through mail-order pharmacies. ${ }^{10-12}$ For example, many third-party payers offer patients a 90-day supply of medication through the mail-order pharmacy for the equivalent of two 30-day supply copayments. Thus, the patient pays $33 \%$ less by using the mail-order pharmacy.

A few studies have examined the effects of Part D on community pharmacies. The Office of the Inspector General (OIG) compared pharmacy reimbursement for Part D prescriptions with pharmacies' drug acquisition costs. ${ }^{13}$ The study found that Part D reimbursement for product acquisition costs exceeded actual pharmacy acquisition costs by an average of $\$ 9.13$ (or 18.1\%) per prescription. In addition, Part D paid pharmacies an average dispensing fee of $\$ 2.27$. This total reimbursement amount represented an average gross margin of $\$ 11.40$, or $18.4 \%$, for Part D prescriptions. Self-reported estimates from 69 of the 99 sampled pharmacies indicated average dispensing costs of $\$ 9.13$ (range $\$ 3.50$ to $\$ 19.00$ ) per prescription. OIG reports that the estimates were based on different methods and that it "was unable to assess the accuracy of those estimates."

The OIG study also found that Part D dispensing fees were about $\$ 2$ less, on average, than those paid by Medicaid. This difference in dispensing fees could partially explain why Part D margins are lower than those paid by Medicaid. However, to fully understand the difference in gross margins, it would be necessary to also know how Medicaid product reimbursement compares with Part D product reimbursement. The OIG study did not examine the effect of Part D on pharmacy sales or the difference between reimbursement and acquisition costs for prescriptions reimbursed by other payers. As a result, the report provided an incomplete picture of the effect of Part D on community pharmacies' profitability.

Radford et al. examined independent pharmacists' early (first 7 post-implementation months) experiences with Part D using semi-structured telephone interviews conducted with 22 rural pharmacies located in 10 states. ${ }^{14}$ Their interviews suggested that gross margins have decreased, prescription volume has increased, but prescription sales have remained flat. However, this study provided qualitative results based on pharmacists impressions and opinions rather than specifically measuring Part D's effects on pharmacy profitability through examination of financial records. 
A report posted on the website of the Center for Pharmaceutical Marketing and Management at the University of Mississippi details the results of Reisetter et al.'s study of the effects of Part D on the profits of community pharmacies. ${ }^{9}$ The study compared 300 pairs of matched prescriptions from 10 pharmacies located throughout the United States. One prescription from each pair was reimbursed by Part D in 2006; the matching prescription was for the same product and quantity, but reimbursed by cash, Medicaid, or a private third-party plan in 2005. The authors estimated Part D gross margins at $18.6 \%$ compared with $24.0 \%$ for prescriptions reimbursed by a combination of cash, Medicaid, and private third-party plans, and concluded that the decline in gross margin resulting from Part D implementation would decrease the net income of the typical community pharmacy by $21 \%$. The study was limited in that it was based on a small sample of prescriptions from 10 pharmacies. Further, the analysis did not consider potential changes in prescription volume due to increased insurance coverage and mail-order usage.

Winegar and colleagues examined changes in gross margins when prescriptions switched from Medicaid to Part D coverage. ${ }^{8}$ Their results were based on data taken from a sample of 313 independent pharmacies in Texas. After adjusting for inflation, the average gross margin fell from $26.7 \%$ (Medicaid payment) to $20.4 \%$ (Part D payment). The gross margins in Texas independent community pharmacies for the top 5 prescription drug program sponsors ranged from $12.0 \%$ to $19.8 \%$ in 2006 , prior to adjustment to 2005 dollars. The study did not consider changes in margins for cash or private third-party prescriptions. It also did not consider Part D-related changes in prescription volume.

There are at least 2 reasons that managed care organizations should be interested in the financial viability of independent pharmacies. First, over the last several years, the growth of Medicaid managed care and the implementation of Medicare Part D have substantially increased the number of managed care patients living in rural and inner city areas. Independent pharmacies are more likely to be located in these areas. ShambaughMiller et al. note, for example, that in 2007, 2,019 independent pharmacies were the only pharmacies in their community. Of these, 1,044 were located at least 10 miles from the next nearest pharmacy. ${ }^{15}$ In order to provide rural and inner-city patients with convenient access and adequate pharmacy services, managed care organizations need both urban and rural pharmacies in their networks. Second, managed care organizations' ability to negotiate discounts on reimbursement rates with pharmacies depends on the number of pharmacies in a market area; as the number of pharmacies declines, so too does the ability of managed care organizations to negotiate discounts.

\section{Objective}

The purpose of this study was to provide a preliminary estimate of the effects of Medicare Part D on the profitability of independent community pharmacies.

\section{Methods}

A financial model was constructed to predict the impact of the Medicare Part D program on independent community pharmacies' profitability. Stahl suggests that models are used when research based on primary data collection or direct observation is not feasible, in order to better understand or predict the system or phenomena under study, and in order to aid decision making. ${ }^{16}$ Based on these considerations, estimating the impact of Part D seems well suited to a modeling approach.

Using research based on primary data collection to study the impact of Part D on pharmacy profits would be extremely difficult. Because almost all pharmacies participate in Part D, it would be difficult, if not impossible, to find an adequate control group. Measuring the effects of Part D using a pre-post design without a control group would provide results that were confounded by changes in the environment, including changes in reimbursement rates of other third-party payers, changes in sales caused by factors other than Part D, changes in the ratio of brand-name to generic drug sales, and changes in competition such as the Wal-Mart $\$ 4$ generic program. While it would be possible to examine certain aspects of Part D's effects on community pharmacies, as has been done by the OIG ${ }^{13}$ Radford et al., ${ }^{14}$ Reisetter et al., ${ }^{9}$ and Winegar et al., ${ }^{8}$ it would be much more difficult to design a study that examined all of the major effects of Part D.

A model, by comparison, is able to make estimates that are free of the effects of confounding variables by varying only those variables that are affected by Part $\mathrm{D}$. In addition, a model is able to take data from disparate sources and use them in a single, comprehensive analysis. A model is also useful because it explores and explains relationships in the system. ${ }^{17}$ The model used in this study, for example, examines and quantifies the relationships between changes in profits and changes in reimbursement rates, increases in prescription sales, and increases in mail-order usage. The model shows how these components relate to each other and the magnitude of the impact of each change on pharmacy profit.

\section{Model Overview}

The model estimated the impact of Medicare Part D on the profitability of a typical independent pharmacy using non-peerreviewed data sources, which were the only data sources currently available. First, key financial metrics (sales, cost of goods sold, operating expenses, number of prescriptions dispensed, and average price per prescription) were drawn from NCPA survey data for 2005, the year prior to Part D implementation. Payer mix for 2005-the percentage of prescriptions attributable to each of 3 payer sources (Medicaid, private third-party insurance, and out-of-pocket spending by individuals with no prescription coverage) — was also derived from the NCPA survey. Second, IMS national market share data were used to estimate rates of conversion from the other 3 payment sources to Medicare Part D. The estimated changes in market share after Part D implementation 
were calculated by applying the conversion rates to the 2005 market share percentages. Third, IMS market share data and other sources were used to estimate other changes in utilization associated with Part D, including both increases in utilization associated with Part D coverage and decreases in community pharmacy sales associated with shifts to mail-order pharmacy use. Fourth, the gross margins for each payer type were applied to the market share data to calculate a new overall gross margin. Finally, the changes in gross margin and utilization were applied to the typical independent pharmacy's income statement for 2005 to estimate net profit for 2006.

\section{Data Sources}

Data for the model were taken from the 2006 NCPA-Pfizer Digest (which provides data for calendar year 20056), and Medicare Part D-the First Year, a marketing research report published by IMS for calendar year 2006 data. $^{3}$ The Digest provided financial information for a national sample of 431 independent pharmacies for 2005, the year immediately preceding implementation of Part D. (In this paper, the pharmacy described by the average values in the Digest will be referred to as the typical independent pharmacy.) The Digest provided input values for 2005 as shown in Tables 1-3. These 2005 input values included information on revenues, expenses, and average prescription price (Table 1); percent of prescriptions dispensed by payer for Medicaid, private third-party payers, and cash (Table 2); and gross margin percentages by payer (Table 3). Data for the Digest were collected by an annual survey of the owners of independent pharmacies that had been in business for at least 1 complete year. All pharmacies in the sample were "pharmacist-owned, privately held businesses." The sample may include, in addition to traditional single-store community pharmacies, long-term care, specialty, and compounding pharmacies. The sample may also include independent pharmacies that are franchise operations or that are located in supermarkets. Owners were asked to complete and submit a questionnaire covering demographic and non-financial information and to complete forms that provided balance sheet and income statement information. Much of the data in the Digest-such as prescription and other sales, gross margins, and expenses-were calculated directly from the financial information provided. However, some data-such as estimates of prescription volume and gross margins by payer-were based on owners' estimates. The extent to which owners based these estimates on data or judgment is not known.

Medicare Part D-The First Year (IMS) included estimates of the rates of conversion of prescriptions to Part D payment by previous payer and of increases in utilization for Part D patients by prior payer (Table 2). ${ }^{3}$ The IMS report was based on information from a proprietary database covering over 5,400 commercial and Medicare health plans. IMS data were based on prescriptions dispensed in both community and mail-order pharmacies.

As discussed earlier, the model assumed that Part D affected
TABLE 1) Income Statement for Typical Independent Pharmacy Before and After Implementation of Medicare Part D

\begin{tabular}{|c|c|c|c|c|}
\hline & \multicolumn{2}{|c|}{$\begin{array}{c}2005^{\mathrm{a}} \\
\text { (Model Input) }\end{array}$} & \multicolumn{2}{|c|}{$\begin{array}{l}2006 \text { Estimated } \\
\text { (Model Output) }\end{array}$} \\
\hline & $\$$ & $\%$ & $\$$ & $\%$ \\
\hline \multicolumn{5}{|l|}{ Sales } \\
\hline Prescription & $3,210,239$ & 92.1 & $3,191,592$ & 92.1 \\
\hline Other $^{\mathrm{b}}$ & $\underline{275,363}$ & 7.9 & $\underline{275,363}$ & 7.9 \\
\hline Total & $3,485,602$ & 100.0 & $3,466,955$ & 100.0 \\
\hline \multicolumn{5}{|l|}{ Cost of Goods Sold } \\
\hline Prescription & $2,481,749$ & 77.3 & $2,490,903$ & 78.0 \\
\hline Other $^{\mathrm{b}}$ & $\underline{181,251}$ & 65.8 & $\underline{181,251}$ & 65.8 \\
\hline Total & $2,663,000$ & 76.4 & $2,672,154$ & 77.1 \\
\hline \multicolumn{5}{|l|}{ Gross Margin } \\
\hline Prescription & 728,490 & 22.7 & 700,689 & 22.0 \\
\hline Otherb & $\underline{94,112}$ & 34.2 & $\underline{94,112}$ & 34.2 \\
\hline Total & 822,602 & 23.6 & 794,801 & 22.9 \\
\hline Operating Expenses ${ }^{\mathrm{b}}$ & $\underline{693,634}$ & 19.9 & $\underline{693,634}$ & 20.0 \\
\hline Net Income Before Tax & 128,968 & 3.7 & 101,167 & 2.9 \\
\hline Number Rxs dispensed & 52,352 & & 52,550 & \\
\hline Average per-Rx price & $\$ 61.32$ & & $\$ 60.67$ & \\
\hline $\begin{array}{l}\text { Average per-Rx cost } \\
\text { of goods sold } \mathrm{b}\end{array}$ & $\$ 47.40$ & & $\$ 47.40$ & \\
\hline \multicolumn{5}{|c|}{$\begin{array}{l}\mathrm{b} \text { To estimate financial change associated with Part } D \text {, the model held constant } \\
\text { (i.e., assumed no change in) nonprescription sales, cost of nonprescription goods } \\
\text { sold, per-prescription cost of goods sold, and pharmacy operating expenses. } \\
N C P A=\text { National Community Pharmacists Association; Rx=prescription. }\end{array}$} \\
\hline
\end{tabular}

the profitability of community pharmacies in 3 ways: (a) increasing sales by providing drug insurance to previously uninsured patients, (b) decreasing sales by inducing patients to use mailorder pharmacies, and (c) decreasing gross margin. The estimation of each of these effects is discussed below.

\section{Estimation of Increased Prescription Utilization Due To Insurance}

The number of new prescriptions that patients purchased as a result of Part D was estimated as the product of the number of prescriptions converted from other payers to Part $\mathrm{D}$ and the post-Part $\mathrm{D}$ increases in utilization by previous payer (Table 2). (The term "new" in this sense means prescriptions that the patient would not have purchased if s/he did not have Part D coverage.)

The data used to calculate conversion rates of prescriptions from cash, Medicaid, or private third-party plans to Part D payment were adapted from IMS figures. IMS reported that the percentages of prescriptions reimbursed by each payer at the end of 2005 were $16.1 \%$ paid by Medicaid, $72.0 \%$ paid by private third-party plans and $12.0 \%$ paid by cash; by the end of 
TABLE 2 Medicare Part D-Induced Increases in Prescription Volume, Prescriptions Lost to Mail Order, Net New Prescription Volume, and Payer Mix After Part $D^{a}$

\begin{tabular}{|c|c|c|c|c|c|c|c|c|c|c|c|}
\hline & $\begin{array}{l}2005 \mathrm{Rx} \\
\text { Volume }\end{array}$ & $\begin{array}{c}\% \text { Rxs } \\
\text { Converted } \\
\text { to Part } D^{c}\end{array}$ & $\begin{array}{c}\text { Rxs } \\
\text { Converted } \\
\text { to Part D }\end{array}$ & $\begin{array}{c}\% \text { Increase } \\
\text { in Rx Use } \\
\text { Due to } \\
\text { Part Dd }\end{array}$ & $\begin{array}{c}\text { New Rx } \\
\text { Volume } \\
\text { Induced by } \\
\text { Part D }\end{array}$ & $\begin{array}{c}\% \text { of Rxs } \\
\text { Converted } \\
\text { to Mail } \\
\text { Order } \\
\text { Due to } \\
\text { Part De }\end{array}$ & $\begin{array}{c}\text { Rxs } \\
\text { Subject to } \\
\text { Conversion } \\
\text { to Mail Order } \\
\text { Due to } \\
\text { Part De }\end{array}$ & $\begin{array}{l}\text { Rxs } \\
\text { Lost } \\
\text { to Mail } \\
\text { Order }\end{array}$ & $\begin{array}{c}\text { Net New } \\
\text { Rx Volume } \\
\text { Induced by } \\
\text { Part } D^{f}\end{array}$ & $\begin{array}{l}\text { Total Rx } \\
\text { Volume } \\
\text { After } \\
\text { Part Dg }\end{array}$ & $\begin{array}{l}\text { Payer Mix } \\
\text { After } \\
\text { Part D } \\
(\%)\end{array}$ \\
\hline $\begin{array}{l}\text { Column Number } \\
\text { (C) }\end{array}$ & 1 & 2 & 3 & 4 & 5 & 6 & 7 & 8 & 9 & 10 & 11 \\
\hline Calculation & & & $\mathrm{C} 1 \times \mathrm{C} 2$ & & $\mathrm{C} 3 \times \mathrm{C} 4$ & & & $\mathrm{C} 6 \times \mathrm{C} 7$ & C5-C8 & C1-C3 ${ }^{g}$ & $\begin{array}{c}\mathrm{C} 10 / \mathrm{C} 10 \\
\text { column } \\
\text { total }\end{array}$ \\
\hline \multicolumn{12}{|l|}{ Payer } \\
\hline Medicaid & 12,041 & 64.7 & 7,791 & 0 & 0 & 0 & 0 & 0 & 0 & 4,250 & 8.1 \\
\hline Private third party & 33,505 & 11.2 & 3,742 & 7 & 262 & 20 & 262 & 52 & 210 & 29,763 & 56.6 \\
\hline Cash & 6,806 & 10.5 & 718 & 23 & 165 & 20 & 883 & 177 & -12 & 6,088 & 11.6 \\
\hline Part D & na & na & na & na & na & na & na & na & na & 12,449 & 23.7 \\
\hline Total & 52,352 & & 12,251 & & 427 & & & 229 & 198 & 52,550 & 100.0 \\
\hline
\end{tabular}

a Numbers shown in the table may not exactly multiply or sum to totals shown because of rounding.

b Source: NCPA-Pfizer Digest 2006. 6

c Source: IMS. ${ }^{3}$ Interpreted as, for example, $64.7 \%$ of prescriptions that would have been reimbursed by Medicaid in 2005 (prior to Part D) were reimbursed by

Medicare Part D in 2006. See text for explanation of how conversion percentages were estimated.

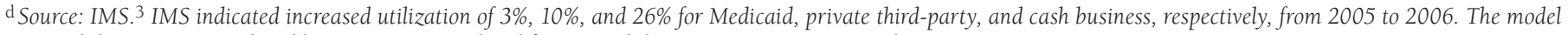
assumed that 3\% was attributable to non-Part D-related factors and the remaining amount was due to Part D.

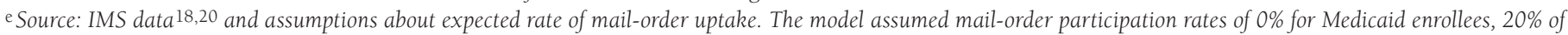

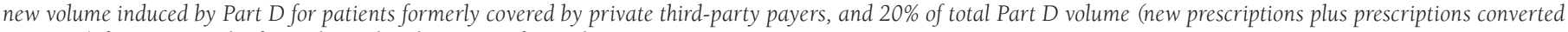
to Part D) for patients who formerly paid cash. See text for explanation.

${ }^{\mathrm{f}}$ Column represents amount of net new volume induced and paid by Part D after offsets for mail-order utilization; rows represent previous payer (e.g., a net increase of 210 new prescriptions now paid by Part D for patients who previously were enrolled with private third-party payers).

g Medicaid, private third-party payers, and cash: 2005 volume minus Rxs converted to Part D (Column 1 minus Column 3).

Part D: Rxs converted to Part D plus net new Rx volume induced by Part D (total Column 3 plus total Column 9).

na = not applicable; NCPA = National Community Pharmacists Association; $R x=$ prescription.

2006 these percentages had changed to $8.7 \%$ paid by Medicaid, $65.9 \%$ paid by private third-party plans, and $10.9 \%$ paid by cash. ${ }^{3}$ However, these percentages included changes attributable both to conversion of prescriptions to Part D and to increased utilization. Because IMS reported separately both percentages of prescriptions covered and rates of increased utilization by payer, it was possible to calculate approximate conversion rates, by payer, that reflected only conversions to Part D and not increases in utilization. For example, IMS reported that the private thirdparty insurance share of prescriptions decreased from $72.0 \%$ in 2005 to $65.9 \%$ in 2006 and that utilization increased 10\% among these patients who converted from third-party insurance to Part D. Thus:

Change in share $=($ original share for payer $\times$ conversion rate $)+$ (original share for payer $\times$ conversion rate $\times$ increased utilization rate). $72.0-65.9=(72.0 \times$ conversion rate $)+(72.0 \times$ conversion rate $\times 0.10)$.

Conversion rate $=7.7 \%$

After removing the changes due to increased utilization, the conversion rates (that is, the percentage of prescriptions by payer converted to Part D) were $44.6 \%$ for Medicaid prescriptions, $7.7 \%$ for private third-party prescriptions and $7.3 \%$ for cash prescriptions.

These figures could not be entered directly into the present study's model because the sample of pharmacies in the IMS report included all types of community pharmacies (chain, independent, food store) as well as mail-order pharmacies. To the extent that independent pharmacies serve a higher proportion of older patients than do other types of community pharmacies, more of the independent pharmacies' patients will be eligible for Part D. Consequently, the conversion rate of cash, Medicaid, and private third-party prescriptions to Part D payment may be higher in independent pharmacies than in the IMS sample. $\mathrm{NCPA}^{7}$ and IMS $^{3}$ estimates of the proportions of prescriptions reimbursed by Part D provide support for this hypothesis. The IMS report indicates that $14.6 \%$ of prescriptions in all community and mailorder pharmacies were reimbursed by Part D in 2006. ${ }^{3}$ The NCPA Digest - which includes only independent pharmacies_-indicates that, for the same time period, 24\% of prescriptions were reimbursed by Part D. ${ }^{7}$ 
Applying the IMS conversion rates to the 2005 NCPA market share data would have resulted in an estimated market share percentage of approximately 16\% for Part D. To account for the higher rate of conversions in independent pharmacies, the conversion rates reported by IMS were increased by 45 percent so that the percentage of prescriptions reimbursed by Part D as estimated in the model was $23.7 \%$, approximately equal to the rate of $24 \%$ that was reported in the 2007 NCPA Digest. The conversion rates used in the study, reflecting the $45 \%$ adjustment, were $64.7 \%$ for Medicaid prescriptions, $11.2 \%$ for private third-party prescriptions, and $10.5 \%$ for cash prescriptions (Table 3). A sensitivity analysis examined the effects of varying conversion rates by $25 \%$ above and below these figures.

The IMS report provides estimates of increases in total utilization by previous payer. ${ }^{3}$ For example, Part D recipients who previously paid cash used 26\% more prescriptions in 2006 than in 2005. The number of prescriptions dispensed annually has been increasing for many years. ${ }^{18}$ Consequently, it is unreasonable to assume that the total increase in utilization from 2005 to 2006 was due to Part D. To adjust for this problem, the estimates of Part-D induced increases in utilization used in the model were 3 percentage points lower than the estimates of increased utilization supplied by IMS. This adjustment was based on the following logic: IMS data indicated that utilization among Part D recipients who also received Medicaid increased by 3\% from 2005 to 2006. There is no reason to expect that the switch to Part D would have increased utilization by Medicaid patients, because Part D plans do not provide more generous coverage or lower copayments than Medicaid. Consequently, the model initially assumed that Part D-related increases were 3 percentage points lower than the total increases measured by IMS.

Yin and colleagues have reported that Part D resulted in increases in utilization (pills per day) of about $1.1 \%$ for Part D eligible patients for the first 5 months of 2006 and about 5.9\% for the following 7 months. ${ }^{5}$ These data yield an approximate $3.9 \%$ increase for the year. These results were based on data from a national chain pharmacy. Given that about $14.6 \%$ of all prescriptions were reimbursed by Part D in 2006 according to IMS data, ${ }^{3}$ a $3.9 \%$ increase in utilization among Part D eligible patients would equate to about a $0.57 \%$ increase in total prescription volume. A 5.9\% increase for Part D patients would yield a 0.86\% increase in total volume. Given this range, a sensitivity analysis in the present study examined the effects on pharmacy profitability of Part D-related increases in prescription volume from 0\%-1\% of total prescription volume.

\section{Estimation of Decreased Prescription Volume Due to Mail-Order}

As indicated earlier, Part D could decrease a community pharmacy's sales as a result of increases in the number of prescriptions dispensed through mail-order pharmacies. The Takeda Prescription Drug Benefit Cost and Plan Design Survey Report indicated

\begin{tabular}{|c|c|c|c|c|}
\hline yer & $\begin{array}{l}\text { Payer Mix } \\
\text { in } 2005^{a} \\
\text { (\% of total } \\
\text { prescrip- } \\
\text { tions) }\end{array}$ & $\begin{array}{c}\text { Average } \\
\text { Gross } \\
\text { Margin in } \\
2005^{\mathrm{a}}(\%)\end{array}$ & $\begin{array}{l}\text { Payer Mix } \\
\text { in } 2006^{b} \\
\text { (\% of total } \\
\text { prescrip- } \\
\text { tions) }\end{array}$ & $\begin{array}{l}\text { Average } \\
\text { Gross } \\
\text { Margin in } \\
2006^{c}(\%)\end{array}$ \\
\hline dicaid & 23.0 & 20.8 & 8.1 & 20.8 \\
\hline vate third partyd & 64.0 & 19.3 & 56.6 & 19.3 \\
\hline h & 13.0 & 42.8 & 11.6 & 42.8 \\
\hline t D & 0.0 & na & 23.7 & 18.5 \\
\hline $\mathrm{al} / \mathrm{mean}$ & 100.0 & 22.7 & 100.0 & 22.0 \\
\hline
\end{tabular}

a Source: NCPA-Pfizer Digest 2006. 6 The 2006 Digest reports data for the previous calendar year, 2005. Gross margins for cash payers were not reported directly in the Digest; they were calculated algebraically using the overall prescription gross margin and, for all other payers, the payer's gross margin weighted by its market share.

b Source: Table 2.

${ }^{c}$ The gross margin for Part D is estimated as detailed in the text. Gross margins for the other payers are assumed to be the same as in 2005. The mean overall prescription gross margin is the mean of the gross margins for each payer weighted by the proportion of prescriptions reimbursed by that payer.

${ }^{\mathrm{d}}$ The 2006 NCPA-Pfizer Digest ${ }^{6}$ indicated that $5 \%$ of prescriptions were reimbursed through Medicare drug discount cards in 2005. The model assumed that prescriptions reimbursed through drug discount cards would have been processed as private third-party prescriptions and would have appeared as private third-party prescriptions in IMS data. As a result, prescriptions reimbursed by Medicare drug discount cards were considered to be private third-party prescriptions in the model. na =not applicable; NCPA = National Community Pharmacists Association.

that $12 \%$ of prescriptions in plans with voluntary mail-order programs were dispensed through mail-order pharmacies in 2006 and 2007.10,19 The information in the Takeda reports is based on a national survey of benefit managers in employersponsored health plans.

IMS Health indicates that $22 \%$ of all non-institutional prescription sales ${ }^{18}$ and $7 \%$ of all non-institutional prescriptions ${ }^{20}$ were dispensed through mail-order pharmacies in 2006. (Noninstitutional prescriptions refer to those dispensed in chain and independent pharmacies, food store pharmacies, and mail-order pharmacies; they do not include prescriptions dispensed in clinics, health maintenance organizations, hospitals, federal facilities, long-term care facility pharmacies, or by home health agencies.) Given that mail-order prescriptions are typically for 90-day supplies, and community pharmacy prescriptions are typically for 30-day supplies, ${ }^{21}$ it seems likely that each mail-order prescription in the IMS data would be comparable to 3 community pharmacy (30-day) prescriptions. The fact that IMS's estimates of mail-order prescription dollar sales were about 3 times higher than the estimate of numbers of mail-order prescriptions supports this hypothesis.

The estimate needed in the model was the percentage of noninstitutional prescriptions dispensed by mail-order pharmacies 
for private third-party plans. IMS data indicate the percentage of non-institutional prescriptions dispensed by mail-order pharmacies for all payers—cash, Medicaid, and private third-party. The following procedure was used to estimate the percentage of non-institutional prescriptions dispensed by mail-order pharmacies for private third-party plans. First, it was assumed that all mail-order prescriptions are reimbursed by private third-party plans; that is, essentially no Medicaid or cash prescriptions are dispensed by mail. Second, because mail order accounts for $22 \%$ of prescription dollar sales, it was assumed that mail order accounts for about $22 \%$ of the total number of 30 -day equivalent prescriptions dispensed by all payers. Third, IMS data indicate that private third-party plans reimbursed $72 \%$ of prescriptions dispensed in 2006. ${ }^{20}$ Given these assumptions, it was estimated that mail order dispensed $(22 \% / 72 \%=) 30 \%$ of non-institutional, third-party plan prescriptions (30-day equivalents).

Based on these estimates, the model initially assumed that $20 \%$ of prescriptions dispensed for patients formerly paying cash or covered by private third parties would be dispensed through mail-order pharmacies. The figure was varied from 10\% to 35\% in a sensitivity analysis.

The model assumed that the extent of increased mail-order use would differ according to the patients' source of payment prior to Part D. The financial incentive to use mail-order pharmacy usually takes the form of lower patient copayments. Copayments for low-income patients, such as those on Medicaid, are substantially lower than those for patients with higher incomes. ${ }^{12}$ Because copayments are lower, the financial incentives to use mail-order pharmacy would be correspondingly weaker. ${ }^{22}$ Further, patients enrolled in both Medicaid and Medicare ("dual-eligibles") can change Medicare Part D plans every 30 days. ${ }^{23}$ Because of this policy, plans may be reluctant to allow these patients to obtain 90-day supplies of medications. Recent research based on data from the Medical Expenditure Panel Survey documents low use of mail-order pharmacies by patients with public insurance..$^{22}$ As a result, the model assumed that no prescriptions for Medicaid patients would be dispensed through mail-order pharmacies.

A community pharmacy would be expected to lose the largest proportion of prescriptions to mail-order pharmacy for those Part D patients who previously paid cash. Prior to Part D, few, if any, of these patients' prescriptions would be dispensed through mail-order pharmacies. ${ }^{22}$ After Part D, all of these patients' prescriptions would be subject to dispensing through the mail. Thus, the model assumed that $20 \%$ of all prescriptions for Part D patients who previously paid cash would be dispensed through mail-order pharmacies. This assumption was based on the rate of $20 \%$ of all third-party prescriptions being dispensed through the mail that was discussed earlier.

A community pharmacy would be expected to experience a smaller shift of prescriptions to mail-order for Part D patients whose prescriptions were previously reimbursed by private third-party programs. These patients would have been subject to strong financial incentives to use mail-order pharmacy prior to being covered by Part D. As a result, the model assumed that any prescriptions that they chose to have dispensed in a community pharmacy before implementation of Part D would continue to be filled in a community pharmacy after implementation of Part D. However, any new prescriptions dispensed as a result of Part D coverage would be subject to dispensing through mail-order. Therefore, the model estimated community pharmacies' loss of prescriptions to mail-order pharmacy from these patients to be $20 \%$ of any new prescription volume resulting from Part D coverage.

To sum up, the number of prescriptions lost to mail-order as a result of Part D was estimated as 20\% of all Part D prescriptions dispensed for patients who previously paid out-of-pocket and $20 \%$ of new, Part D-induced prescriptions for patients who previously had private third-party coverage (Table 2).

\section{Estimation of Change in Prescription Gross Margin Percentage}

A pharmacy's prescription gross margin percentage is determined by the relative proportion of prescriptions reimbursed by each payer-cash, Medicaid, private third-party plans, Part D-and the average gross margin percent earned on prescriptions reimbursed by each payer. To estimate the change in the typical community pharmacy's gross margin percentage, the model first estimated the change in the percentage of prescriptions covered by each payer after implementation of Medicare Part D (Tables 2 and 3).

The model initially used a gross margin percent of $18.5 \%$ for Part D prescriptions. This approximates the gross margins estimated in studies by the $\mathrm{OIG}^{13}$ and Reisetter et al. ${ }^{9}$ A sensitivity analysis examined the effects of varying the gross margin paid by Part D plans from $16 \%$ to $21 \%$. The lower margin-16\%-is the margin reported in the 2007 NCPA-Pfizer Digest for Part D prescriptions; $^{7}$ the higher margin-21\%—is slightly above that estimated by Winegar et al. ${ }^{8}$

The typical community independent pharmacy's prescription gross margin percentage, after implementation of Medicare Part D, was then calculated as the average of the gross margins earned from each payer weighted by the proportion of the pharmacy's prescription volume represented by each payer (Table 3).

\section{Estimation of Overall Effect on Profitability}

The average prescription price after implementation of Part D was estimated based on the new gross margin percentage, assuming no change to the per-prescription cost of goods sold (Table 4). Post-implementation prescription volume (number of prescriptions) was calculated as pre-implementation (2005) prescription volume plus the Part D-induced increase in prescription volume less the Part D-induced loss of prescriptions to mail-order pharmacies (Tables 2 and 4). Post-implementation prescription 


\section{TABLE 4 Calculation of Average Prescription Price, Prescription Sales, and Prescription Cost of Goods Sold After Part D Implementation}

\begin{tabular}{|c|c|}
\hline Post-Implementation Average Prescription Price & \\
\hline Pre-Part D average prescription price & $\$ 61.32$ \\
\hline Pre-Part D average prescription gross margin percent & $\times 22.7 \%$ \\
\hline Pre-Part D average prescription gross margin dollars & $\$ 13.92$ \\
\hline Pre-Part D average prescription price & $\$ 61.32$ \\
\hline Pre-Part D average prescription gross margin dollars & -13.92 \\
\hline Average prescription cost of goods sold & $\$ 47.40$ \\
\hline Average prescription cost of goods sold & $\$ 47.40$ \\
\hline Post-Part D prescription gross margin percent ${ }^{\mathrm{a}}$ & $\underline{22.0 \%}$ \\
\hline Post-Part D average prescription price & $\$ 60.73$ \\
\hline Post-Implementation Prescription Sales & \\
\hline Pre-Part D prescription volume (\# of prescriptions) & 52,352 \\
\hline Part D-induced change in prescription volume & +198 \\
\hline Post-Part D prescription volume & 52,550 \\
\hline Post-Part D average prescription price & $\times \$ 60.73$ \\
\hline Post-Part D prescription sales & $\$ 3,191,592^{b}$ \\
\hline $\begin{array}{l}\text { Post-Implementation Prescription Cost of } \\
\text { Goods Sold }\end{array}$ & \\
\hline Pre-Part D prescription volume & 52,352 \\
\hline Part D-induced change in prescription volume & +198 \\
\hline Post-Part D prescription volume & 52,550 \\
\hline Average prescription cost of goods sold & $\times \$ 47.40$ \\
\hline Total prescription cost of goods sold & $\$ 2,490,903^{c}$ \\
\hline $\begin{array}{l}\text { a Formulae: } G M D=(G M P \times C O G S) /(1-G M P)=(0.220 \times 47.40) \\
\qquad \text { Price }=G M D+C O G S=\$ 13.37+\$ 47.40=\$ 60.77 \text {, } \\
\text { where GMD = post-Part } D \text { gross margin dollars, GMP = post-Par } \\
\text { percent, and COGS =cost of goods sold (per prescription). Total } \\
\text { different from the figure reported due to rounding error. Assume } \\
\text { prescription cost of goods sold does not change from pre-implem } \\
\text { post-implementation. Lower prescription price reflects only the } \\
\text { margin percent. } \\
\text { b The product of the calculation using the numbers shown in the } \\
\$ 3,191,362 \text {. This result is somewhat lower than the true produc } \\
\text { due to rounding and the large values in the calculation. } \\
\text { CThe product of the calculation using the numbers shown in the } \\
\text { This result is somewhat lower than the true product of } \$ 2,490,9 \\
\text { and the large values in the calculation. }\end{array}$ & $\begin{array}{l}-0.220)=\$ 13.37 \text {. } \\
\text { gross margin } \\
\$ 60.77 \text { is } \$ 0.04 \\
\text { lat the average } \\
\text { ation to } \\
\text { inge in gross } \\
\text { ble is } \\
\$ 3,191,512 \\
\text { le is } \$ 2,490,870 \text {. } \\
\text { due to rounding }\end{array}$ \\
\hline
\end{tabular}

sales were estimated as post-implementation prescription volume multiplied by post-implementation average prescription price (Table 4). Post-implementation cost of goods sold was estimated as post-implementation prescription volume multiplied by the average per-prescription cost of goods sold (which was assumed to be the same both pre- and post-implementation; Table 4). The model assumed no Part D-related change in operating expenses.

\section{Sensitivity Analysis}

One-way sensitivity analyses were used to determine the extent to which uncertainty in individual variables affected the final
TABLE 5 One-Way Sensitivity Analyses of Effects of Medicare Part D on the Net Profit of the Typical Independent Community Pharmacy

\begin{tabular}{c|c|c}
\hline Variable & $\begin{array}{c}\text { Net Income } \\
(\$)\end{array}$ & $\begin{array}{c}\text { Change From } \\
\text { Pre-Part D } \\
\text { Net Income (\$) }\end{array}$ \\
\hline Part D gross margin \% & & \\
\hline 16 & 77,131 & $-51,837$ \\
\hline 17 & 86,702 & $-42,266$ \\
\hline $18.5^{a}$ & 101,167 & $-27,801$ \\
\hline 19 & 106,018 & $-22,950$ \\
\hline 21 & 125,571 & $-3,397$ \\
\hline
\end{tabular}

Conversion rates as \% of IMS Health adjusted estimates ${ }^{b}$

\begin{tabular}{c|c|c}
\hline 75 & 108,121 & $-20,847$ \\
\hline $100^{a}$ & 101,167 & $-27,801$ \\
\hline 125 & 94,250 & $-34,718$ \\
\hline
\end{tabular}

Part D-related change in prescription volume (as \% of total prescription volume)

\begin{tabular}{c|c|c}
\hline 0 & 99,058 & $-29,910$ \\
\hline $0.38^{\mathrm{a}}$ & 101,167 & $-27,801$ \\
\hline 0.50 & 101,858 & $-27,110$ \\
\hline 1.00 & 104,659 & $-24,309$ \\
\hline
\end{tabular}

Mail order conversion rate \%

\begin{tabular}{c|c|c}
\hline 10 & 102,386 & $-26,582$ \\
\hline $20^{a}$ & 101,167 & $-27,801$ \\
\hline 30 & 99,948 & $-29,020$ \\
\hline 35 & 99,339 & $-29,629$ \\
\hline
\end{tabular}

andicates the value used in the base-case analysis.

$\mathrm{b}$ The adjusted IMS Health estimates of conversion rates by payer are shown in

Table 2. The adjustment amounts and rationale are discussed in the text.

estimate from the model. Probabilistic sensitivity analyses were used to consider the effects of uncertainty in multiple variables simultaneously and to incorporate the probabilities associated with the uncertainty in each variable. One-way sensitivity analyses examined the effects of assumptions about gross margin, rates of conversion to Part D from other reimbursement sources, change in total prescription volume related to Part D, and the mail-order conversion rate, using the input values shown in Table 5. The variables, values, and probabilities used in the probabilistic sensitivity analysis are shown in Table 6 . The probabilistic sensitivity analysis was conducted using a Monte Carlo simulation with 1,000 iterations using Microsoft Excel 2003 (Microsoft, Redmond, Washington, 2003).

\section{Results}

The model estimated that $23.7 \%$ of prescriptions dispensed by the typical independent community pharmacy were reimbursed by Medicare Part D in 2006 (Tables 2 and 3). The vast majority of these prescriptions would have otherwise been reimbursed 
TABLE 6 Values Used in Probabilistic Sensitivity Analysis

\begin{tabular}{l|c|c}
\hline Variable & $\begin{array}{c}\text { Value of } \\
\text { Variable }\end{array}$ & $\begin{array}{c}\text { Probability } \\
\text { Associated } \\
\text { With Value }\end{array}$ \\
\hline Part D gross margin & $16 \%$ & 0.25 \\
\hline & $18.5 \%$ & 0.50 \\
\hline $\begin{array}{l}\text { Conversion rate } \\
\text { (\% of IMS estimate) }\end{array}$ & $21 \%$ & 0.25 \\
\hline & $75 \%$ & 0.25 \\
\hline $\begin{array}{l}\text { Part-D related change in prescription } \\
\text { volume (\% of total prescription volume) }\end{array}$ & $100 \%$ & 0.50 \\
\hline & $125 \%$ & 0.25 \\
\hline $\begin{array}{l}\text { Mail order conversion rate (\% of } \\
\text { prescriptions) }\end{array}$ & $10 \%$ & 0.25 \\
\hline
\end{tabular}

a The IMS estimates of conversion rates by payer are shown in Table 2 .

by Medicaid, private third-party plans, or cash. The change in payer mix, combined with the lower gross margin on Part D prescriptions, resulted in an estimated decrease in the typical independent community pharmacy's gross margin from $22.7 \%$ in the year before implementation of Part D to $22.0 \%$ in the year following implementation (Table 3).

The model estimated that implementation of Part D resulted in covered patients using an additional 427 prescriptions (Table 2). However, an estimated 229 prescriptions converted to or induced by Part D that otherwise would have been dispensed by the community pharmacy were instead dispensed through mail-order pharmacies. Thus, the typical independent community pharmacy's net Part D-induced increase in volume was 198 prescriptions per year. The typical pharmacy's estimated total prescription volume after Part D was 52,550. Thus, Part D induced an increase in prescription volume of $0.38 \%$ (198/52,353).

As a result of the effect of the decreased gross margin for Part D prescriptions, along with the small net increase in prescription sales, the typical pharmacy's estimated prescription sales decreased by $\$ 18,647$, from $\$ 3,210,239$ to $\$ 3,191,592$, as a result of Medicare Part D (Table 1). The pharmacy's cost of goods sold increased by $\$ 9,154$ as a result of dispensing an additional 198 prescriptions. The net effect was a decrease of $\$ 27,801$, or $21.6 \%$, in the pharmacy's pretax net income. Thus, lower reimbursement rates from Part D plans had a much greater effect on pharmacy profits than did either the increase in utilization resulting from increased insurance coverage or the change in use of mail-order pharmacies.

\section{Sensitivity Analysis}

The results of one-way sensitivity analyses are shown in Table 5 . Within the ranges tested, the factor with the greatest effect on profitability was the gross margin earned on Part D prescriptions. If Part D plans yielded a 16\% gross margin, the typical pharmacy's net income would have declined by $\$ 51,837$ in 2006; if Part D plans yielded a $21 \%$ gross margin, the typical pharmacy's net income would have declined by only $\$ 3,397$. The effects of variations in the rate of mail-order usage, conversion of prescriptions to Part $\mathrm{D}$, and increased utilization induced by Part D were much smaller for the ranges tested.

The probabilistic sensitivity analysis (results not shown in tables) indicated that the typical pharmacy's net income would decline by a mean (SD) of $\$ 27,651$ ( $\$ 5,310)$, approximately $22 \%$ (4\%), per year as a result of Part D. The $25^{\text {th }}, 50^{\text {th }}$, and $75^{\text {th }}$ quartiles for change in net income were $-\$ 30,348,-\$ 27,801$, and $-\$ 22,653$. The minimum and maximum values were $-\$ 39,151$ and $-\$ 16,991$. The latter figure indicated that even under the most favorable assumptions, the typical pharmacy's net income declined as a result of Part $\mathrm{D}$. The analysis also estimated a mean (SD) net income of $\$ 101,414(\$ 5,420)$ and $25^{\text {th }}, 50^{\text {th }}$, and $75^{\text {th }}$ percentiles of $\$ 98,620, \$ 101,167$, and $\$ 106,315$. Minimum and maximum net incomes were $\$ 89,817$ and $\$ 111,977$. The minimum value suggests that even under the least favorable conditions, the typical independent pharmacy remained profitable.

\section{Discussion}

The financial model developed in this study estimated that the typical independent, community pharmacy realized a mean (SD) 22\% (4\%) decline in net income as a result of Medicare Part D. The model examined 3 ways that Part D might affect pharmacy profitability: increased sales resulting from greater utilization induced by Part D coverage, reduced gross profit margins on prescriptions converted from other payers to Part D, and decreased sales from increased use of mail order among Part D recipients. The model indicated that increased insurance coverage resulted in only a small increase in prescription utilization, probably because a large majority of Part D recipients had prescription coverage before joining Part D. IMS estimated that $86 \%$ of Part D enrollees had some type of prescription insurance before enrolling in Part D. ${ }^{3}$ Neuman et al. estimated that two-thirds of the elderly had prescription insurance before the implementation of Part D. ${ }^{1}$

The model also indicated that increased use of mail-order pharmacies did not have a major impact on community pharmacy profits. This outcome was likely a result of several factors: low use of mail-order pharmacies among Medicaid patients, the small effect of Part D in inducing new prescription use, and the relatively small number of previously cash-paying patients that enrolled in Part D.

The factor having the greatest impact on pharmacy profitability was the decrease in gross margin from lower Part D 
reimbursement rates. This outcome occurred because the great majority of prescriptions dispensed for Part D, over 98\% based on the estimates in Table 2, would have been reimbursed by other payers at higher gross margins had Part D not been implemented.

Sensitivity analyses revealed no scenario-over the ranges tested-in which net profit increased as a result of Part D. Even the best-case scenario produced a small negative effect on net profit. Model results were not sensitive, over the ranges tested, to the rate of mail-order prescription use, the rate at which prescriptions were converted to Part D from other payers, or increased utilization induced by Part D coverage. The insensitivity to mail-order usage was probably a result of the small increase in prescription volume related to Part D and the low rate of conversion of cash to Part D prescriptions. Because estimated volume increased only minimally, even Part D mail-order usage of 35\% would have small effects on profitability.

The model was much more sensitive to variations in Part D reimbursement rates. Each 1 percentage point decrease in the gross margin earned on Part D prescriptions decreased the pharmacy's profit by about $\$ 9,600$ per year (Table 5). The trend in pharmacy reimbursement in private plans has been negative over the past decade. ${ }^{10}$ The results of this analysis suggest increasing pressure on pharmacy profits from Part D in the future.

While the results indicated that the typical pharmacy suffered a substantial reduction in profits as a result of Part D, they also indicated that the loss was not large enough to put the typical pharmacy out of business in any of the scenarios modeled. However, because no information on the distribution of pharmacies by profitability was available, it was not possible to estimate the number of pharmacies that would be put out of business by Part D.

The model's results apply to the "typical" or "average" independent community pharmacy. Pharmacies with substantial populations of elderly patients whose prescriptions were reimbursed by cash or Medicaid before implementation of Part D would have seen much larger negative effects. Pharmacies in rural or inner city areas, which dispense greater proportions of cash and Medicaid prescriptions, would be particularly hard hit by Part D.

The results of the present study also underscore the growing importance to community pharmacies of finding non-product related sources of revenue. Over the last 2 decades, the proportion of prescriptions reimbursed by third-party payers has increased ${ }^{24,25}$ as the rates of reimbursement from these payers have decreased. ${ }^{10,26}$ The conversion of elderly, cash-paying consumers to third-party coverage under Part D was only the latest step in this trend. The trend clearly indicates that dispensing prescriptions will continue to be less and less profitable for community pharmacies, and that the future of community pharmacy lies less in dispensing and more in patient-care services such as medication therapy management.

\section{Limitations}

The results of the study are limited in that they are based on a model. To the extent that the data used in the model are not representative, the study may provide misleading results. Most of the data used in the study came from sources that were not peerreviewed (IMS ${ }^{3}$ and the NCPA-Pfizer Digest ${ }^{6}$ ). Further, estimates of payer mix and gross margins by payer were based on owners' self-reports. It is not known whether these data were based on judgment or actual financial information. Further, the main data sources for the study, IMS and the Digest, provided point estimates of input values without providing measures of error. On the other hand, the data used in the model came from a national sample of 431 independent community pharmacies (as reported in the Digest) and a large, national study of Part D-related changes in prescription use as reported by IMS, a commonly cited reference source. Data from the Digest have been used extensively in studies examining the finances of independent community pharmacies, and IMS is a world-wide leader in the provision of prescription use data. Finally, the model included extensive sensitivity analyses to examine the effects of variations in model inputs.

The model's results are based on a number of assumptions. The major assumptions were based on estimates taken from the literature and were examined in sensitivity analyses. The results were relatively insensitive to variations in all of the parameters examined except Part D reimbursement rates. However, even the most optimistic assumption about Part D reimbursement showed a decrease in the typical pharmacy's net income.

Much of the decrease in profitability associated with Part D resulted from lower gross margins paid by Part D compared with other payers. Part of the difference in gross margins between Part D and other payers could be attributable to different rates of generic drug use, which would lead to different prescription gross margins because pharmacies earn substantially greater margins on generic drugs than on branded drugs. For example, Winegar et al. found gross margins for brand-name drugs of $8.7 \%$ for Medicaid and 8.3\% for Part D. For generics, margins were 39.9\% for Medicaid versus $29.5 \%$ for Part D. ${ }^{8}$ Data provided in the OIG report indicate gross margins of $8.9 \%$ for brands versus $48.0 \%$ for generics. ${ }^{13}$ (These figures are not reported by OIG but can be calculated from the acquisition cost-reimbursement cost differences and dispensing fees that are reported.) However, the evidence to date indicates that generic usage rates in Part D are similar to, or slightly higher than, those in commercial or Medicaid plans. Winegar et al. indicate that use of generics was not significantly different between Medicaid and Medicare patients in their study. ${ }^{8}$ Wolters Kluwer reports that by January, 2007, 63\% of Part D claims were dispensed with generics as compared with $59 \%$ of private third party plans. ${ }^{27}$ The OIG report indicates similar rates of generic drug usage between Part D and Medicaid plans. ${ }^{13}$ Thus, it seems unlikely that margin differences between Part D and other payers result from differing rates of generic drug use. 
The payer mix predicted by the model for 2006 differed from the actual payer mix reported in the 2007 NCPA-Pfizer Digest. The predicted and NCPA-reported percentages of prescriptions by payer were, respectively, $23.7 \%$ and $24 \%$ for Part D, $11.6 \%$ and 9\% for cash, $56.6 \%$ and $52 \%$ for private third party, and $8.1 \%$ and $15 \%$ for Medicaid. While this discrepancy may appear to be a significant limitation, it is probably not reasonable to expect that the 2 sources would provide the same estimates. The model assumed that the only change in the pharmacy environment between 2005 and 2006 was the implementation of Part D. The NCPA estimates, which are based on real-world data and conditions, reflected all changes in the pharmacy environment. These included, for example, changes in Medicaid eligibility requirements, changes in employers' willingness to offer private coverage for drugs, increases in patient cost sharing, changes in reimbursement rates of other third-party payers, and changes in competition such as the Wal-Mart $\$ 4$ generic program.

As discussed in the Methods section, the model assumed that no Part D prescriptions for Medicaid patients would be dispensed through mail-order pharmacies. To the extent that Medicaid patients did use mail-order pharmacies, the negative effects on pharmacy profitability would be larger than estimated by the model. However, given the historically low use of mail order in public insurance programs ${ }^{22}$ and the lower copayments charged to Medicaid patients (compared with non-Medicaid patients) in Part D plans, ${ }^{28}$ it seems unlikely that mail-order use would constitute a sizeable proportion of total Part D utilization by Medicaid patients.

\section{Conclusions}

A financial model based on a national sample of independent community pharmacies indicated that Part D has had a substantial and negative effect on the profitability of community pharmacies. This outcome has resulted primarily from the lower reimbursement rates that pharmacies receive for Part D prescriptions. However, the typical pharmacy remained profitable even in the worst case scenario.

\section{Author}

NORMAN V. CARROLL, PhD, is Professor, Virginia Commonwealth University School of Pharmacy, Richmond, Virginia.

AUTHOR CORRESPONDENCE: Norman V. Carroll, PhD, Professor, Virginia Commonwealth University School of Pharmacy, 410 North 12th Street, Box 980533, Richmond, VA 23298-0533. Tel.: 804.828.2587; E-mail: nvcarroll@vcu.edu

\section{DISCLOSURES}

This research was not funded, and the author declares no conflicts of interest related to the subject of this article including financial interests, grants, consulting relationships, gifts, stock holdings, or honoraria.

\section{REFERENCES}

1. Neuman P, Strollo MK, Guterman S et al. Medicare prescription drug benefit progress report: Findings from a 2006 national survey of seniors. Health Aff (Millwood). 2007;26(5):w630-w643.

2. Statistical Abstract of the United States: 2006. Table 7. Resident Population by Age and Sex: 1980 to 2006. U.S. Census Bureau website Available at: www.census.gov/compendia/statab/tables/08s0007.pdf. Accessed August 29, 2008.

3. IMS Health. Medicare Part D: The First Year. Plymouth Meeting, PA: IMS; 2007.

4. The Medicare prescription drug benefit: Fact Sheet. Kaiser Family Foundation Web Site. Available at: www.kff.org/medicare/upload/7044_08 pdf. Accessed June 4, 2008.

5. Yin W, Basu A, Zhang JX, Rabbani A, Meltzer DO, Alexander GC. The effect of the Medicare Part D prescription drug benefit on drug utilization and expenditures. Ann Intern Med. 2008;148:169-77.

6. NCPA-Pfizer Digest 2006. Alexandria, VA: National Community Pharmacists Association; 2006.

7. NCPA-Pfizer Digest 2007. Alexandria, VA: National Community Pharmacists Association; 2007.

8. Winegar AL, Shepherd MD, Lawson K, Richards K. The impact of Medicare Part D on the percent gross margin earned by Texas independent pharmacies for dual eligible beneficiary claims. Paper presented at: ISPOR 13th Annual Meeting; May 5, 2008; Toronto, Ontario, Canada. Available at: www.ispor.org/awards/13meet/presentations/MD2.pdf. Accessed September 9, 2008

9. Reisetter BC, Dunson DH, Kolassa EM, Schwab P. Effect of Medicare Part D reimbursement on community pharmacy profitability. University of Mississippi School of Pharmacy. Available at: www.pharmacy.olemiss.edu/ cpmm/CPFreport.pdf. Accessed September 9, 2008.

10. Pharmacy Benefit Management Institute. The Takeda Prescription Drug Benefit Cost \& Plan Design Survey Report: 2007 Edition. Scottsdale, AZ: Pharmacy Benefit Management Institute, Inc.; 2007.

11. Pharmacy Benefit Management Institute. The Takeda Prescription Drug Benefit Cost \& Plan Design Survey Report: 2005 Edition. Scottsdale, AZ: Pharmacy Benefit Management Institute, Inc.; 2006.

12. Understanding Medicare Reform: What Pharmacists Need to Know. Monograph 4: Final Regulations for Medicare Part D. Washington, DC: American Pharmacists Association; 2005.

13. Levinson, DR. Review of the Relationship Between Medicare Part D Payments to Local, Community Pharmacies and the Pharmacies' Drug Acquisition Costs (A-06-07-00107). Office of the Inspector General Website. Available at: www. oig.hhs.gov/oas/reports/region6/60700107.pdf. Accessed September 4, 2008. 14. Radford A, Slifkin R, Fraser R, Mason M, Mueller K. The experience of rural independent pharmacies with Medicare Part D: Reports from the field. J Rural Health. 2007;23(4):286-93.

15. Shambaugh-Miller MD, Vanosdel N, Mueller KJ. Reliance on Independently Owned Pharmacies in Rural America (Policy Brief No. 2007-6). Omaha, NE: RUPRI Center for Rural Health Policy Analysis; 2007.

16. Stahl JE. Modelling methods for pharmacoeconomics and health technology assessment. Pharmacoeconomics. 2008;26(2):131-48.

17. Weinstein MC, O'Brien B, Hornberger J et al. A report of the ISPOR Health Science Committee-Task Force on Good Research PracticesModeling Studies. Value Health. 2003;6:9-17.

18. Channel Distribution by U.S. Sales. IMS Health Webpage. Available at: www.imshealth.com/deployedfiles/imshealth/Global/Content/Document/ Top-Line\%20Industry\%20Data/2007\%20Channel\%20Distribution\%20 by\%20Sales_2.pdf. Accessed September 8, 2008.

19. Pharmacy Benefit Management Institute. The Takeda Prescription Drug Benefit Cost \& Plan Design Survey Report: 2006 Edition. Scottsdale, AZ: Pharmacy Benefit Management Institute, Inc.; 2006. 
20. Channel Distribution by U.S. Dispensed Prescriptions. IMS Health Webpage. Available at: www.imshealth.com/deployedfiles/imshealth/ Global/Content/Document/Top-Line\%20Industry\%20Data/ 2007\%20Channel\%20Distribution\%20by\%20RXs.pdf. Accessed September 8, 2008.

21. Pharmacy Benefit Managers: Ownership of Mail-Order Pharmacies. Washington, DC: Federal Trade Commission; 2005.

22. Stagnitti MN. Comparing population characteristics of persons purchasing prescribed drugs from mail order pharmacies with persons purchasing prescribed drugs from other outlets, 2005. MEPS Webpage. Available at: www.meps.ahrq.gov/mepsweb/data_files/publications/st200/ stat200.pdf. Accessed February 28, 2008.

23. Dual Eligibles and Medicare Part D. Washington, DC: Kaiser Family Foundation; 2008.
24. IMS America. IMS Class-of-Trade Analysis 1995. Totowa NJ: IMS America; 1995.

25. IMS Health Inc. DDD Annual Class-of-Trade Analysis 2003. Plymouth Meeting, PA: IMS Health Inc.; 2004.

26. Novartis Pharmacy Benefit Report—Facts \& Figures, 2002 Edition. East Hanover, NJ: Novartis Pharmaceuticals; 2002

27. Pieri S, Belazi D. Medicare Part D—Market Dynamics. Wolters Kluwer Website. Available at: http://download.lww.com/wolterskluwer_vitalstream_ com/PermaLink/Whitepaper\%207-2008.pdf. Accessed August 29, 2008.

28. Medicare: Low-income assistance under the Medicare drug benefit. Kaiser Family Foundation. Available at www.kff.org/medicare/upload/ 7327_04.pdf. Accessed September 8, 2008. 